\title{
PENGARUH PERHATIAN ORANGTUA TERHADAP HASIL BELAJAR SISWA PADA MATA PELAJARAN MATEMATIKA DI KELAS IV SD NEGERI 097350 PARBUTARAN SIMALUNGUN
}

\author{
Saurma Sihombing, Regina Sipayung, Darinda Sofia Tanjung \\ Surel: saurmasihombingnababan@gmail.com
}

\begin{abstract}
This study aims to determine the effect of parental attention on student learning outcomes in mathematics class IV at SD Negeri 097350 Parbutaran Simalungun in the learning year 2020/2021. In the research, researchers used quantitative methods. The population of this study were all fourth grade students of SD Negeri 097350 Parbutaran Simalungun, totaling 32 people. The research sample of 32 people was determined using the Non Probability Sampling technique, namely total sampling so that all members of the population as the research sample used the t-test on SPSS ver 22.0. The results of this study indicate that the results of correlation testing can be seen in the correlation coefficient value of 0.732 which means $r_{\text {count }}(0.732) \geq r_{\text {table }}$ (0.349), then Ha is accepted. So there is a strong influence between parental attention on student learning outcomes in grade IV SD Negeri 097350 Parbutaran Simalungun. It can also be seen from the results of the $t$-test hypothesis testing where $t_{\text {count }} \geq t_{\text {table, }}$ namely $5.891 \geq 1.697$, so it states that the hypothesis Ha is accepted. This shows the effect of parental attention on student learning outcomes in grade IV SD Negeri 097350 Parbutaran Simalungun for the 2020/2021 academic year.
\end{abstract}

Keywords: Influence, Parental Attention, Learning Outcomes

\begin{abstract}
ABSTRAK
Penelitian ini bertujuan untuk mengetahui pengaruh perhatian orangtua terhadap hasil belajar siswa pada mata pelajaran matematika kelas IV di SD Negeri 097350 Parbutaran Simalungun tahun pembelajaran 2020/2021. Pada penelitian peneliti menggunakan metode kuantitatif. Populasi penelitian ini seluruh siswa kelas IV SD Negeri 097350 Parbutaran Simalungun yang berjumlah 32 orang. Sampel penelitian sebanyak 32 orang yang ditentukan menggunakan teknik Non Probability Sampling yakni Sampling total sehingga seluruh anggota populasi sebagai sampel penelitian menggunakan uji-t pada SPSS ver 22.0. Hasil penelitian ini menunjukkan bahwa hasil pengujian korelasi dapat dilihat pada nilai koefisien korelasi sebesar 0,732 artinya $\mathrm{r}_{\text {hitung }}$ $(0,732) \geq \mathrm{r}_{\text {tabel }}(0,349)$ maka $_{\mathrm{a}}$ diterima. Maka terdapat pengaruh yang kuat antara perhatian orangtua terhadap hasil belajar siswa di kelas IV SD Negeri 097350 Parbutaran Simalungun. Dapat juga dilihat dari hasil pengujian hipotesis uji-t dimana $t_{\text {hitung }} \geq t_{\text {tabel }}$ yaitu $5,891 \geq 1,697$ sehingga menyatakan bahwa hipotesis $\mathrm{H}_{\mathrm{a}}$ diterima. Hal ini menunjukkan adanya pengaruh perhatian orangtua terhadap hasil belajar siswa di kelas IV SD Negeri 097350 Parbutaran Simalungun Tahun Pembelajaran 2020/2021.
\end{abstract}

Kata Kunci: Pengaruh, Perhatian orangtua, Hasil Belajar 



\section{PENDAHULUAN}

Pendidikan merupakan suatu proses belajar individu yang berlangsung sepanjang hayat. Dengan pendidikan, individu akan mampu mengembangkan potensi dan kemampuan yang dipengaruhi oleh kebiasaan yang baik, membentuk kepribadian yang cakap dan terampil. Pendidikan merupakan kebutuhan utama sebagai bekal manusia untuk masa depan, maka dari itu sudah selayaknya mendapatkan perhatian, penanganan dan prioritas oleh pemerintah, masyarakat, keluarga dan seluruh pelaku pendidikan. Anak yang menjalani proses pendidikan memerlukan peran dan dukungan dari keluarga.

Orangtua merupakan pendidik utama dan pertama bagi anak-anak mereka, karena dari merekalah anak menerima pendidikan. Dengan demikian bentuk pertama dari pendidikan terdapat dalam kehidupan keluarga. Orangtua selain sebagai pendidik juga sebagai pembimbing dan penanggung jawab anaknya. Orangtua memiliki peran yang sangat besar bagi anaknya supaya tidak terjerumus ke hal-hal yang tidak baik. Orangtua harus mampu membimbing serta mengajarkan hal-hal yang baik, sesuai dengan nilai dan norma yang berlaku di masyarakat.

Orangtua tentu sangat peduli terhadap pendidikan anak-anaknya. Sebagian besar orangtua bercita-cita agar anaknya mendapat pendidikan setinggi-tingginya sehingga tidak heran jika para orang tua mencari lembaga pendidikan yang tentunya dianggap baik untuk putra-putrinya. Orangtua mungkin lupa bahwa lembaga pendidikan pertama dan utama untuk menjadikan anaknya menjadi manusia yang manusiawi adalah keluarga. Keluarga merupakan salah satu faktor yang dapat mempengaruhi belajar siswa dan akan berdampak pada hasil belajarnya

Hasil belajar adalah suatu hasil yang diperoleh siswa setelah siswa tersebut melakukan kegiatan belajar dan pembelajaran serta bukti keberhasilan yang telah dicapai oleh seseorang yang mencakup aspek kognitif, afektif, maupun psikomotor. Banyak faktor yang mempengaruhi hasil belajar anak salah satunya yaitu perhatian orangtua. Orangtua perlu memperhatikan perubahan-perubahan sikap perilaku yang terjadi pada anaknya yang masih membutuhkan bimbingan dan arahan dari orangtua dengan memberikan perhatian, terutama perhatian pada kegiatan belajar mereka dirumah. Akan tetapi orang tua kurang menyadari pentingnya perhatian orangtua akan mempengaruhi hasil belajar anak. Bagaimana pun sibuknya orang tua harus meluangkan waktu untuk memberikan perhatian kepada anak setiap hari.

$\begin{array}{rrr}\begin{array}{r}\text { Setiap } \\ \text { menjalankan }\end{array} \text { proses } & \begin{array}{r}\text { yang } \\ \text { belajar }\end{array}\end{array}$ memerlukan peran dan dukungan dari orangtua. Misalnya, memenuhi kebutuhan psikologis anak dengan memberikan perhatian, menyediakan fasilitas belajar anak di rumah, suasana dan ketentraman di rumah serta memperhatikan kesehatan anak. Anak 
yang selalu mendapatkan bimbingan dari orangtua akan membuat mereka menjadi semakin rajin belajar, terutama anak usia sekolah dasar (sekitar 6-12 tahun) masih memerlukan bimbingan dan pengawasan dari orangtua.

Belajar adalah suatu proses perubahan perilaku yang muncul karena pengalaman. Belajar bukan hanya mengingat akan tetapi lebih luas dari pada itu, yakni mengalami, hasil belajar bukan suatu penguasaan hasil latihan melainkan perubahan kelakuan, kegiatan belajar dapat dihayati (dialami) oleh orang yang sedang belajar dan juga dapat diamati oleh orang lain. Belajar adalah proses perubahan tingkah laku dalam diri seseorang, baik dari segi pengetahuan, sikap, dan ketrampilan yang ditimbulkan melalui latihan atau pengalaman.

\section{Tabel 1. Kerangka Berpikir}

\begin{tabular}{|c|c|}
\hline Perhatian Orangtua (x) & \\
\hline$>$ Memberikan bimbingan belajar & Hasil Belajar Siswa (y) \\
\hline$>$ Pengawasan terhadap belajar & $>$ Domain kognitif \\
\hline $\begin{array}{l}\text { Pemberian penghargaan dan } \\
\text { hukuman }\end{array}$ & Domain afektif \\
\hline$>$ Pemenuhan kebutuhan belajar & Domain \\
\hline $\begin{array}{l}\text { Menciptakan suasana belajar yang } \\
\text { tenang dan tentram }\end{array}$ & \\
\hline Memperhatikan kesehatan anak & \\
\hline $\begin{array}{l}\text { Menanamkan rasa tanggung jawab } \\
\text { kepada anak }\end{array}$ & \\
\hline
\end{tabular}

\section{METODE PENELITIAN}

Dalam penelitian ini terdapat dua variabel yaitu variabel bebas dan variabel terikat. Variabel bebas pada penelitian ini adalah perhatian orangtua (variabel $\mathrm{X}$ ) sedangkan Variabel terikat dalam penelitian ini adalah hasibelajar siswa (variabel Y).
Jika melakukan suatu penelitian harus memerlukan populasi. Populasi adalah wilayah generalisasi yang terdiri atas obyek/subyek yang mempunyai kualitas dan karakteristik tertentu yang ditetapkan oleh peneliti untuk dipelajari dan kemudia ditarik kesimpulannya (dalam buku Sugiyono 2018:80). 
Sampel adalah sebagian dari jumlah dan karakteristik yang dimiliki oleh populasi tersebut. Menurut Sugiyono (2018:81) "sampel adalah bagian dari jumlah dan karakteristik yang dimiliki oleh populasi tersebut. Bila populasi besar, dan peneliti tidak mungkin mempelajari semua yang ada pada populasi, misalnya karena keterbatasan dana, tenaga dan waktu, maka peneliti dapat menggunakan sampel yang diambil dari populasi itu.
Apa yang dipelajari dari sampel itu, kesimpulannya akan dapat diberlakukan untuk populasi. Untuk itu sampel yang akan diambil dari populasi harus betul-betul repsesentatif (mewakili)". Dalam penelitian ini sampel yang digunakan adalah Non probability sampling yaitu teknik sampling total. Sampling total adalah sampling yang menjadikan seluruh anggota populasi sebagai sampel penelitian.

Tabel 2. Kelas dan Jumlah Siswa

\begin{tabular}{cc}
\hline Kelas & Jumlah Siswa \\
\hline Kelas IV & 32 \\
Jumlah & 32 \\
\hline
\end{tabular}

Data primer adalah data yang diperoleh peneliti secara langsung (dari tangan pertama) melalui angket kuesioner dan data sekunder merupakan sumber data yang tidak langsung diberikan kepada pengumpul data. Dalam penelitian ini menggunakan sumber data primer yang didapat langsung dari sumber subjek penelitian.
Pengumpulan data dilakukan dengan memberi kuesioner kepada siswa. Sebelum responden mengisi kuesioner, peneliti meminta responden untuk melihat arahan untuk mengisi kuesioner. Setelah itu, responden dipersilahkan mengisi kuesioner yang telah disediakan, yaitu kuesioner Perhatian Orangtua terhadap Hasil Belajar dan kuesioner tersebut dikumpulkan pada hari itu juga.

Tabel 3. Kisi-kisi Instrumen Penelitian

\begin{tabular}{|c|c|c|c|c|}
\hline Variabel Penelitian & Indikator & $\begin{array}{c}\text { Positif } \\
(+)\end{array}$ & $\begin{array}{l}\text { Negatif } \\
(-)\end{array}$ & Jumlah \\
\hline \multirow{7}{*}{$\begin{array}{l}\text { Perhatian Orangtua } \\
\text { dalam kegiatan } \\
\text { belajar anak }\end{array}$} & Memberikan Bimbingan Belajar & $1,5,7$ & $2,4,6$ & 7 \\
\hline & Pengawasan Terhadap Belajar & $9,11,13,15,17,19,21$ & $8,10,12,14,16,18,20,22$ & 13 \\
\hline & $\begin{array}{l}\text { Pemberian Penghargaan dan } \\
\text { Penghukuman }\end{array}$ & $23,25,27,29$ & $24,26,28$ & 7 \\
\hline & Pemenuhan Kebutuhan Belajar & 31,33 & 30,32 & 4 \\
\hline & $\begin{array}{l}\text { Penciptaan Suasana Belajar yang } \\
\text { nyaman dan tentram }\end{array}$ & $35,37,39,41$ & $34,36,38,40,42$ & 9 \\
\hline & Memperhatikan Kesehatan anak & 43,45 & 44,46 & 4 \\
\hline & $\begin{array}{l}\text { Menanamkan rasa tanggung } \\
\text { jawab }\end{array}$ & 47,49 , & 48,50 & 4 \\
\hline \multicolumn{3}{|c|}{ Jumlah } & & 50 \\
\hline
\end{tabular}


Skala Likert digunakan untuk mengukur sikap, pendapat, dan persepsi seseorang atau sekelompok orang tentang fenomena sosial. Dengan kisaran 1-54 dengan alternatif jawaban, yaitu: "1 = Tidak Pernah", "2 = Ragu-ragu" "3 = Sering" " $4=$ Selalu" "5.

Tabel 4. Skor Alternatif Jawaban

\begin{tabular}{cc}
\hline Alternatif Jawaban & $\begin{array}{c}\text { Skor Untuk } \\
\text { Pertanyaan }\end{array}$ \\
\hline Selalu & 4 \\
Sering & 3 \\
Ragu-ragu & 2 \\
Tidak Pernah & 2 \\
\hline
\end{tabular}

Dokumentasi adalah suatu teknik pengumpulan data dengan menghimpun dan menganalisis dokumen tertulis maupun tidak tertulis.

Instrumen yang baik apabila memenuhi syarat sebagai instrumen yang standar. Instrumen yang standar apabila instrumen itu valid atau tepat. Adapun rumusnya sebagai berikut:

$$
r_{x y}=\frac{N \sum X Y-(\Sigma X)(\Sigma Y)}{\sqrt{\left\{N \sum X^{2}-(\Sigma X)^{2}\right\}\left\{N \sum Y^{2}-(\Sigma Y)^{2}\right\}}} \cdots
$$

(Arikunto, 2018: 87)

Keterangan:

$\mathrm{r}_{\mathrm{xy}}=$ koefisien korelasi antara

variabel $\mathrm{x}$ dan $\mathrm{y}$

$\Sigma x y=$ jumlah perkalian $\mathrm{x}$ dengan $\mathrm{y}$

$\mathrm{X}=$ skor tiap item

$\mathrm{Y}=$ skor total

$\mathrm{N}$ = sampel

Rumus pada reliabilitas menggunakan rumus Alpha menurut Arikunto (2018: 122 ) adalah sebagai berikut:

$$
r_{11}=\left(\frac{n}{(n-1)}\right)\left(1-\frac{\sum \sigma_{b}^{2}}{\sigma_{t}^{2}}\right)
$$

Keterangan:

$r_{11}=$ Reliabilitas angket yang dicari

$\sum \sigma_{b}^{2}=$ Jumlah varians skor tiap-tiap item

$\sigma_{t}^{2}=$ Varians total

$\mathrm{n} \quad=$ Banyaknya butir pertanyaan

Analisis statistik dibagi menjadi dua yaitu statistik deskriftif dan statistik inferenssial. Sedangkan analisis non statistik berangkat dari data kualitatif. Pada analisis nonstatistik masalah dilihat dari berbagai segi dan data yang kumpulkan bukan secara random atau mekanik tetapi dikuasai oleh peneliti.

Variabel bebas (X) dan variabel terikat (Y). Dengan berbantuan program SPSS versi 22.0. Uji normalitas dilakukan dengan menggunakan uji Liliefoors, Sudjana (2017: 446-447).

Untuk mencari Fhitung dilakukan dengan bantuan program SPSS versi 22.0. Rumus uji linearitas data adalah sebagai berikut:

$\mathrm{F}_{\text {reg }}=\frac{R K_{\text {reg }}}{R K_{\text {res }}}$

Keterangan :

$\mathrm{F}_{\text {reg }}=$ harga $\mathrm{F}$ untuk garis regresi

$\mathrm{RK}_{\text {reg }}=$ rerata kuadrat garis regresi

$\mathrm{RK}_{\text {res }}=$ rerata kuadrat garis residu

Untuk mengetahui ada tidaknya pengaruh antara variabel bebas (X) dengan variabel terikat (Y), dengan rumus korelasi Product Moment Arikunto (2018: 87) yaitu: 
$r_{x y}=\frac{N \sum X Y-\left(\sum X\right)\left(\sum Y\right)}{\sqrt{\left\{N \sum X^{2}-\left(\sum X\right)^{2}\right\}}\left\{N \sum Y^{2}-\left(\sum Y\right)^{2}\right\}}$

Keterangan:

$\mathrm{r}_{\mathrm{xy}} \quad=$ Koefisien korelasi product moment

$\mathrm{N} \quad=$ Jumlah seluruh siswa

$\sum \mathrm{X}=$ Skor item

$\sum \mathrm{Y}=$ Skor total seluruh siswa

$\sum X Y=$ Jumlah hasil perkalian antara skor "X" dan skor "Y"

Untuk mengetahui apakah variabel $\mathrm{X}$ memiliki pengaruh yang signifikan terhadap variabel $\mathrm{Y}$ dilakukan pengujian terhadap hipotesis dengan menggunakan uji t sebagai berikut: $t=\frac{r \sqrt{\mathrm{n}-2}}{\sqrt{1-r^{2}}}$

(Sugiyono, 2018: 187)

Keterangan:

$r=$ koefisien korelasi

$n=$ sampel

Jika $\mathrm{t}$ hitung $\geq \mathrm{t}$ tabel : hipotesis alternatif diterima

Jika $\mathrm{t}$ hitung $\leq \mathrm{t}$ tabel : hipotesis alternatif ditolak

\section{Pembahasan}

Setelah dilakukan perhitungan dengan menggunakan SPSS Versi 22.0 pengujian normalitas yaitu dengan menggunakan uji KolmogorovSmirnov, diketahui nilai signifikansi $0,05 \%$.

Tabel 5. Uji Normalitas Instrumen

Tests of Normality

\begin{tabular}{l|r|r|r|r|r|r}
\hline & \multicolumn{3}{|c|}{ Kolmogorov-Smirnov ${ }^{\mathrm{a}}$} & \multicolumn{3}{c}{ Shapiro-Wilk } \\
\cline { 2 - 7 } & Statistic & df & \multicolumn{1}{c|}{ Sig. } & Statistic & \multicolumn{1}{c}{ df } & Sig. \\
\hline Perhatian Orangtua & .119 & 32 & $.200^{*}$ & .976 & 32 & .685 \\
Hasil Belajar & .123 & 32 & $.200^{*}$ & .969 & 32 & .473 \\
\hline
\end{tabular}

*. This is a lower bound of the true significance.

a. Lilliefors Significance Correction

Hasil perhitungan uji linaeritas pada variabel bebas dengan variabel terikat pada penelitian ini adalah sebagai berikut:

Tabel 6. Uji Linearitas

ANOVA Table

\begin{tabular}{|c|c|c|c|c|c|c|c|}
\hline & & & $\begin{array}{l}\text { Sum of } \\
\text { Squares }\end{array}$ & df & $\begin{array}{l}\text { Mean } \\
\text { Square }\end{array}$ & $\mathrm{F}$ & Sig. \\
\hline \multirow{5}{*}{$\begin{array}{l}\text { Hasil Belajar * } \\
\text { Perhatian Orangtua }\end{array}$} & \multirow{3}{*}{$\begin{array}{l}\text { Between } \\
\text { Groups }\end{array}$} & (Combined) & 827.208 & 18 & 45.956 & 2.524 & .047 \\
\hline & & Linearity & 533.390 & 1 & 533.390 & 29.299 & .000 \\
\hline & & $\begin{array}{l}\text { Deviation from } \\
\text { Linearity }\end{array}$ & 293.818 & 17 & 17.283 & .949 & .548 \\
\hline & \multicolumn{2}{|c|}{ Within Groups } & 236.667 & 13 & 18.205 & & \\
\hline & \multicolumn{2}{|l|}{ Total } & 1063.875 & 31 & & & \\
\hline
\end{tabular}

Analisis korelasi dengan menggunakan rumus rxy bertujuan untuk membuktikan adanya pengaruh yang signifikan antara variabel $\mathrm{x}$ dengan variabel y. 
Saurma Sihombing, Regina Sipayung, Darinda Sofia Tanjung : Pengaruh ...

Tabel 7. Hasil Uji Korelasi

Perhatian Orangtua terhadap Hasil Belajar Output SPSS

Correlations

\begin{tabular}{ll|r|r}
\hline & \multicolumn{1}{|c|}{$\begin{array}{c}\text { Perhatian } \\
\text { Orangtua }\end{array}$} & \multicolumn{1}{c}{ Hasil Belajar } \\
\hline Perhatian Orangtua & Pearson Correlation & 1 & $.732^{* *}$ \\
& Sig. (2-tailed) & & .000 \\
& $\mathrm{~N}$ & 32 & 32 \\
\hline Hasil Belajar $\quad$ Pearson Correlation & $.732^{* *}$ & 1 \\
& Sig. (2-tailed) & .000 & 32 \\
$\mathrm{~N}$ & 32 & \\
&
\end{tabular}

**. Correlation is significant at the 0.01 level (2-tailed).

Pengujian hipotesis pada penelitian ini dilakukan dengan menggunakan uji $\mathrm{t}$ dengan berbantuan program SPSS Versi 22.0. Uji t digunakan untuk mengetahui ada tidaknya pengaruh variabel bebas terhadap variabel terikat yaitu variabel pola asuh orangtua terhadap motivasi belajar. Pengujian hipotesis dengan menggunakan uji t dilakukan dengan cara membandingkan $t_{\text {hitung }}$ dengan $t_{\text {tabel. }}$ Kriteria pengujian dengan menggunakan uji $\mathrm{t}$ adalah jika $t_{\text {hitung }} \geq$ $t_{\text {tabel }}$ hipotesis alternatif diterima dan jika $t_{\text {hitung }} \leq t_{\text {tabel }}$ hipotesis alternatif ditolak.

Berikut akan disajikan tabel dari hasil pengujian hipotesis dengan berbantuan program SPSS ver 22.0

Tabel 8. Hasil Uji Hipotesis

Coefficients $^{a}$

\begin{tabular}{|c|c|c|c|c|c|c|}
\hline \multirow{2}{*}{\multicolumn{2}{|c|}{ Model }} & \multicolumn{2}{|c|}{ Unstandardized Coefficients } & \multirow{2}{*}{$\begin{array}{c}\text { Standardized } \\
\text { Coefficients }\end{array}$} & \multirow[b]{2}{*}{$\mathrm{t}$} & \multirow[b]{2}{*}{ Sig. } \\
\hline & & $\mathrm{B}$ & Std. Error & & & \\
\hline \multirow[t]{2}{*}{1} & (Constant) & 33.284 & 7.743 & & 4.299 & .000 \\
\hline & Perhatian Orangtua & 472 & .080 & .732 & 5.891 & .000 \\
\hline
\end{tabular}

a. Dependent Variable: Hasil Belajar

\section{Pembahasan}

- Berdasarkan hasil uji normalitas pengolahan data diperoleh nilai signifikansi perhatian orangtua adalah $L_{\text {hitung sebesar } 0,685 \text { dan }}$ hasil belajar Lhitung sebesar 0,473 sedangkan $\mathrm{L}_{\text {tabel }}$ sebesar 0,930 sehingga $\mathrm{L}_{\text {hitung }} \leq \mathrm{L}_{\text {tabel. }}$ Maka dapat disimpulkan bahwa data perhatian orangtua dan hasil belajar siswa berdistribusi normal.
- Berdasarkan hasil uji linearitas antara perhatian orangtua terhadap hasil belajar diperoleh nilai signifikasi $=0,548>0,005$ dan diperoleh $F_{\text {hitung }}=0,949 \leq F_{\text {tabel }}$ $=4,15$, maka dapat disimpulkan bahwa pengaruh antara perhatian orangtua terhadap hasil belajar siswa bersifat linear.

- Berdasarkan hasil uji korelasi penelitian ini menunjukkan bahwa perhatian orangtua memiliki 
pengaruh terhadap hasil belajar siswa hal tersebut terbukti dari nilai $r_{x y} 0,732$ terletak pada rentang nilai $\mathrm{r}$ 0,600 - 0,800 maka dapat disimpulkan tingkat pengaruh antara variabel perhatian orangtua terhadap hasil belajar siswa memiliki pengaruh yang tinggi.

- Berdasarkan hasil pengujian uji hipotesis penelitian ini dapat diketahui nilai $r_{\text {hitung sebesar } 5,891}$ dan $t_{\text {tabel }}$ sebesar 1,697 sehingga $t_{\text {hitung }} \geq t_{\text {tabel }}$ maka Ha diterima yaitu terdapat pengaruh yang positif dan signifikan antara perhatian orangtua terhadap hasil belajar siswa.

\section{SIMPULAN}

Berdasarkan hasil dan pembahasan penelitian tentang pengaruh perhatian orangtua terhadap hasil belajar siswa pada mata pelajaran matematika siswa kelas IV SD Negeri Parbutaran Jl. Simpang Pete Kecamatan Bosar Maligas Kabupaten Simalungun, dengan analisis data dapat disimpulkan sebagai berikut:

- Hasil uji normalitas diketahui $\mathrm{L}_{\text {hitung }} \geq \mathrm{L}_{\text {tabel }}$ yaitu $0,200 \geq 0,156$, maka dapat diketahui data perhatian orangtua terhadap hasil belajar berdistribusi normal.

- Hasil uji linearitas perhatian orangtua terhadap hasil belajar diperoleh nilai signifikasi yaitu $0,548>0,005$ dan $F_{\text {hitung }} \leq \mathrm{F}_{\text {tabel }}$ yaitu $0,949 \leq 4,15$, maka dapat disimpulkan pengaruh perhatian orangtua terhadap hasil belajar bersifat linear
- Hasil uji korelasi perhatian orangtua memiliki pengaruh terhadap hasil belajar siswa terbukti dari nilai $\mathrm{r}_{\mathrm{xy}} 0,732$ terletak pada rentang nilai r 0,700 - 0,900, maka dapat diketahui perhatian orangtua terhadap hasil belajar siswa memiliki pengaruh yang tinggi.

- Hasil uji hipotesis diketahui thitung $\geq t_{\text {tabel }}$ yaitu 5,891 $\geq 1,697$ maka Ha diterima yaitu terdapat pengaruh yang positif dan signifikan antara perhatian orangtua terhadap hasil belajar siswa

\section{DAFTAR RUJUKAN}

Arikunto, S. 2018. Prosedur Penelitian. Jakarta: Rineka Cipta

Djamarah, S. B. 2018. Psikologi Belajar. Jakarta: Rineka Cipta.

Hotmaida, L. 2019. Pengaruh Perhatian Orangtua terhadap Hasil Belajar Siswa pada Mata Pelajaran Matematika Kelas IV SD Negeri 068003 Perumnas Simalingkar Medan. Skripsi, Fakultas Keguruan dan Ilmu Pendidikan Universitas Khatolik Santo Thomas Medan.

Istirani, P. 2018. Ensiklopedia Pendidikan. Medan: Media Persada.

Khairani, M. 2017. Psikologi Belajar. Yogyakarta: Aswajaya

Pressinda.

Mardyah. 2015. Peran Orang Tua dalam Pendidikan Agama terhadap Pembentukan Kepribadian Anak. Vol. 3 No. 2. 
Saurma Sihombing, Regina Sipayung, Darinda Sofia Tanjung : Pengaruh ...

Muhammad, T. 2017. Pengaruh Perhatian Orangtua terhadap Hasil Belajar Siswa Kelas V SD Negeri Se-gugus Jenderal Sudirman Kecamatan Sempor. Jurnal Pendidikan, Edisi 10 Tahun ke-6.

Noor, J. 2017. Metedologi Penelitian. Jakarta: Prenadamedia Group.

Novindra, D. 2017. Peran Orangtua dalam Pendidikan Anak Usia Dini Ditinjau dari Latar Belakang Pendidikan. Jurnal Potensia, Vol. 2 No. 2.

Pramawati, T. 2016. Pengaruh Perhatian Orangtua terhadap Hasil Belajar Matematika Siswa Kelas IV SD Se-Gugus II Kecamatan Kasihan Kabupaten Bantul Tahun Pelajaran 2015/2016. Yogyakarta: Skripsi, Fakultas Keguruan dan Ilmu Pendidikan Universitas PGRI

Rosyid, Z. D. 2019. Prestasi Belajar. Malang: Literasi Nusantara Abadi.

Silaban, P. J. 2015. Meningkatkan Motivasi dan Kemampuan Pemahaman Matematis Siswa melalui Pembelajaran Kooperatif Tipe TGT Berbantuan Alat Peraga pada Mata Pelajaran Matematika di Kelas VI SD Methodist 12 Medan. Jurnal Ilmiah MBP, Vol. 3 No. 2.

Slameto. 2017. Belajar dan Faktorfaktor yang Mempengaruhi. Jakarta: Rineka Cipta.
Sugiyono. 2018. Metode Penelitian Pendidikan. Bandung: Alfabeta. Suntana, I. 2015. Etika Pendidikan Anak. Bandung: Pustaka Setia.

Susanti, L. 2019. Prestasi Belajar Akademik dan Non Akademik. Malang: Literasi Nusantara Abadi.

Susanto, A. 2018. Teori Belajar dan Pembelajaran di Sekolah Dasar. Jakarta: Prenada Media Group.

Umar, M. 2015. Peranan Orangtua dalam Peningkatan Prestasi Belajar Anak. Jurnal Ilmiah Edukasi, Vol. 1 No. 1.

Walgito, B. 2018. Pengantar Psikologi Umum. Yogyakarta: Andi Offset 